Dikirim: 29 Juli 2016 Diterbitkan: 1 Januari 2017

\title{
Perilaku seksual promiskuitas pada remaja laki-laki di Wirobrajan, kota Yogyakarta
}

\section{Promiscuity in sexual behavior in adolescent boys in Wirobrajan, Yogyakarta city}

Hernawan Isnugroho ${ }^{1}$, Atik Triratnawati ${ }^{2}$, Supriyati $^{1}$

\begin{abstract}
Purpose: This study aimed to obtain a description of the factors that promote promiscuity in sexual behavior and its impact in adolescent boys in Wirobrajan. Method: This qualitative research used a case study design, using snowball sampling. Data were analyzed by content analysis technique. Results: The permissiveness of sexual behavior of teenagers will have an impact, and is easily affected by promiscuity behavior. The influence of peer group or peers is very dominant in the behavior of teen promiscuity. Lack of adolescent awareness about the dangers of promiscuity, the orientation of seeking pleasure and curiosity triggers the behavior of teen promiscuity by exploiting loopholes of rules and lack of control. The confidence and experience of the impact of promiscuity behavior becomes the dominant factor so that teenagers who do not behave with promiscuity do not repeat the behavior. Impact of juvenile promiscuity behavior among others included being ostracized, gonorrhea, syphilis, and genital herpes and other sexually transmitted diseases. Conclusions: Greater supervision is needed from various sectors and enforcement of the rules so that the behavior and impact of promiscuity can be minimized. The supervision of teenagers' association will have an impact on adolescent behavior.
\end{abstract}

Keywords: adolescent; promiscuity

\footnotetext{
${ }^{1}$ Departemen Perilaku Kesehatan, Lingkungan dan Kedokteran Sosial, Fakultas Kedokteran, Universitas Gadjah Mada

(Email: nities_satro@yahoo.com)

${ }^{2}$ Departemen Antropologi, Fakultas Ilmu Budaya, Universitas Gadjah Mada
} 


\section{PENDAHULUAN}

Promiskuitas merupakan aktifitas seksual yang dilakukan dengan banyak atau lebih dari satu pasangan yang telah dikenal atau pun baru dikenal (1). Fenomena promiskuitas pada sebagian remaja seperti yang terjadi pada akhir-akhir ini, tidak lepas dari pendidikan seks yang minim pada remaja di keluarga dan di sekolah. Pendidikan seks yang diterima remaja sangat kurang dan mengakibatkan remaja mencari informasi tentang hal yang berhubungan dengan seks dengan orang lain di luar rumah seperti teman (2).

Seseorang yang memiliki sikap lebih permisif terhadap masalah seksualitas cenderung melakukan hubungan seksual pranikah. Hal ini dapat dicegah dengan meningkatkan self efficacy sebagai wujud kemampuan menilai perilaku seks pranikah berisiko (3). Tempat yang paling sering untuk melakukan hubungan seks adalah di rumah kos, rumah pribadi, hotel atau wisma. Responden mengaku bahwa perilaku seksual ini terjadi tanpa paksaan dan didasari rasa kebutuhan, dan responden aktif melakukan hubungan seksual lebih dari satu orang pasangan (3).

Perilaku seksual promiskuitas pada remaja didasari banyak faktor yang memengaruhi (faktor internal dan eksternal) (5). Perilaku seks bebas pada remaja akan menimbulkan beberapa manifestasi, terutama di kalangan remaja. Dampak yang berkaitan dengan perilaku seks bebas ini meliputi masalah penyakit menular seksual termasuk HIV/AIDS (6). Penelitian ini bertujuan memperoleh gambaran tentang faktor yang mendorong kemunculan perilaku seksual promiskuitas dan dampaknya pada remaja laki-laki di kecamatan Wirobrajan kota Yogyakarta.

\section{METODE}

Penelitian ini merupakan penelitian kualitatif dengan rancangan studi kasus. Subjek penelitian ini adalah laki-laki yang memenuhi kriteria inklusi, yang meliputi remaja laki-laki berusia $>18$ tahun, pernah melakukan perilaku promiskuitas, sudah berhenti berperilaku promiskuitas minimal 3 bulan, belum menikah dan tinggal di kecamatan Wirobrajan lebih dari 6 bulan. Model pengambilan subjek penelitian secara teknik snowball sampling. Pengambilan data dengan wawancara mendalam pada subjek untuk mengeksplorasi masalah perilaku promiskuitas. Teknik pengambilan sampel yang dilakukan secara berantai dengan bantuan key informant dan dari key informant inilah akan berkembang sesuai dengan petunjuk.
Proses analisis data yang berintikan penyajian dengan cara mengorganisasi informasi secara sistemik atau open coding untuk mempermudah penelitian dalam menggabungkan dan merangkai keterikatan antar data dalam menyusun penggambaran proses dan fenomena yang ada pada objek penelitian atau selective coding.

Peneliti memberikan informasi mengenai hak dan kewajiban subjek penelitian dan menjamin rahasia informasi yang disampaikan oleh subjek penelitian pada awal penelitian dan informasi yang diberikan subjek penelitian hanya akan digunakan dalam batas kepentingan studi. Kerahasiaan informasi dan hak dan kewajiban subjek penelitian ditulis dalam informed consent.

\section{HASIL}

Perilaku promiskuitas menunjukkan tidak adanya rasa tanggung jawab dan memunculkan permasalahan yang menyebabkan gangguan fisik dan psikososial. Perilaku promiskuitas dapat menyebabkan remaja rentan terhadap HIV/AIDS, dan beberapa penyakit menular seksual (PMS) yang tidak bisa disembuhkan. Beberapa penyakit menular seksual adalah gonnorhea, sifilis, chlamydia dan herpes genitalis. Permasalahan lain akan timbul seperti stres, depresi, kurang percaya diri dan sikap yang tidak bertanggung jawab pada pelaku.

Perilaku promiskuitas merupakan perilaku seks yang dilakukan secara bersama-sama sehingga para pelaku merasa jijik atau kurang nyaman. Cairan dari perempuan sebagai partner seks menjadi faktor utama.

"Ada perasaan jijik, saat dari alat kelamin perempuan mengeluarkan sperma dari laki-laki lain saat aktivitas seksual bersama. Karena satu perempuan melakukan aktivitas seksual dengan banyak laki-laki” (Remaja 1)

Perilaku promiskuitas akan menimbulkan perasaan takut dan was-was. Dampak perilaku tersebut seperti timbul dan tertular penyakit terus membayangi pelaku promiskuitas, akan tetapi para remaja kurang peduli dengan hal tersebut. Para pelaku promiskuitas tetap melakukan perilaku tersebut. Hal ini disebabkan perilaku seksual yang dilakukan merupakan hal yang memuaskan.

"Sebenarnya, saya lebih nyaman berhubungan seks dengan pacar daripada berhubungan seks secara beramai-ramai. Ada perasaan takut dengan risiko penyakit yang ditimbulkan, tapi aktivitas seks seperti itu memuaskan" (Remaja 2) 
Remaja memiliki kecenderungan mencari sensasi seksual yang tinggi. Remaja terus berusaha memenuhi kebutuhan seks dan mengulangi terus-menerus karena merasa puas. Hormon testosteron memengaruhi gairah seks individu. Kecenderungan mencari sensasi seksual yang tinggi membuat seseorang berupaya mencari jalan agar kebutuhan terpenuhi. Pada individu tertentu promiskuitas merupakan pilihan untuk mencari sensasi itu.

"Saya melakukan promiskuitas untuk mencari sensasi beda, karena berhubungan seks dengan pacar sudah biasa” (Remaja 2)

Setiap kebudayaan masyarakat, perilaku seksual diatur dan dimanifestasikan dalam berbagai bentuk peraturan yang dikenal dengan norma, moral, etika dan lain-lain. Peraturan tersebut dapat berbentuk larangan-larangan atau petunjuk, moral etika dan nilai. Tatanan nilai, norma, etika dan peraturan untuk mengontrol perilaku individu agar tidak keluar dari jalur normatif yang berlaku. Ketika jalur normatif dilanggar maka muncul suatu konstruksi kenyataan sosial baru, dianggap menyimpang dari nilai perilaku seks pranikah. Perilaku seks menyimpang di kalangan remaja merupakan salah satu bentuk dari konstruksi sosial (eksternalisasi) dan merupakan fenomena sosial hasil dari interaksi dan kegiatan remaja. Perilaku ini dilakukan berulang kali sehingga melembaga dalam bentuk perilaku menyimpang.

"Aktivitas seksual di kos terjadi sembunyi-sembunyi. Jika ketahuan akan dimarahi ibu kos, karena melanggar aturan kos. Lawan jenis dilarang masuk kamar, kecuali keluarga” (Remaja 3)

Promiskuitas dianggap sikap yang salah karena melanggar norma. Pada penyimpangan jenis ini dorongan seksual yang dijadikan sasaran pemuasan seksual tetap lawan jenis, tetapi caranya bertentangan dengan norma dan etika. Perilaku ini dipandang tidak lazim oleh masyarakat. Pelanggaran norma yang ada di masyarakat akan mendapat cemooh, dikucilkan bahkan hukuman sesuai dengan adat atau aturan lingkungan setempat.

Kemampuan seseorang untuk memotivasi pada diri sendiri sangat diperlukan untuk tidak melakukan sesuatu yang menyimpang. Pengalaman dan keyakinan mendominasi responden untuk tidak melakukan perilaku promiskuitas kembali.

"Keinginan melakukan seksual seperti itu ada, tapi saya sudah berniat berhenti. Kalau diajak, saya tidak mau melakukan, hanya melihat sambil minum-minum saja” (Remaja 1)
Perilaku inisiasi seks pranikah yang diawali oleh berbagai hambatan atau tantangan dari dalam diri dan dari lingkungan. Pengukuran terentang dari "tentu saya dapat menolak" hingga "tentu saya tidak dapat menolak". Dampak dari perilaku promiskuitas sangat beragam meliputi psikologi, fisiologi, sosial dan fisik.

"Setelah melakukan hubungan seksual seperti itu, saya sering memikirkan nya. Saya sering merasa mengantuk saat pelajaran di kelas” (Remaja 1)

"Semenjak saya tahu ada teman yang menderita sifilis, saya tidak berani melakukan hubungan sekseual seperti itu lagi” (Remaja 2)

"Saya merasa badan saya rusak, kesepian dan kepikiran terus-menerus. Ada perasaan tidak karuan” (Remaja 3)

Dampak psikologis sering terlupakan pada saat melakukan free sex atau mengalami dampak fisik akibat free sex. Selalu muncul rasa bersalah, marah, sedih, menyesal, malu, kesepian, tidak punya bantuan, bingung, stres, benci pada diri sendiri, benci pada orang yang terlibat, takut tidak jelas, insomnia (sulit tidur), kehilangan percaya diri, gangguan makan, kehilangan konsentrasi, depresi, berduka, tidak bisa memaafkan diri sendiri, takut akan hukuman Tuhan, mimpi buruk, merasa hampa, halusinasi, dan sulit mempertahankan hubungan.

Orang-orang yang mengetahui seseorang telah melakukan hubungan seks bebas akan dinilai rendah meskipun hanya melakukan satu kali. Seks bebas adalah tindakan yang dilarang agama dan melanggar aturan pemerintah, sehingga wajar jika ada seorang yangmelakukan perbuatan tersebut akan dikucilkan dari lingkungan. Pemahaman agama dan norma yang rendah, kurang pengawasan dan perhatian dari orang tua, tidak ada pendidikan seks sehat dan lingkungan yang dapat mendorong perilaku seks bebas di kalangan remaja adalah faktor penndukung remaja berperilaku seksual menyimpang. Peningkatan kasus pornografi dan pornoaksi melalui media informasi menjadi faktor perilaku seksual menyimpang. Dampak psikologis dari perilaku seksual remaja di antaranya adalah timbulnya perasaan marah, takut, rendah diri, bersalah, dan merasa berdosa dan berkaitan dengan kecemasan atau depresi. Selain itu, dampak sosial dapat bervariasi dari dikucilkan sampai dicemooh oleh masyarakat.

\section{BAHASAN}

Promiskuitas merupakan tindakan seksual yang sangat immoral, secara terbuka tampak sangat kasar, mencolok mata, dilakukan banyak laki-laki, sehingga ditolak masyarakat. Perilaku permisif seksual banyak 
dilakukan remaja. Perilaku seksual adalah manifestasi dorongan hidup manusia yang bersifat naluriah dan merupakan segala tingkah laku yang didorong oleh hasrat seksual baik dengan lawan jenis dan dengan sesama jenis. Bentuk tingkah laku ini umum dimulai dari sikap yang bermacam-macam mulai dari tertarik, berkencan dan bersanggama (7).

Anak yang lebih tua memiliki berbagai ketakutan yang berhubungan dengan diri atau status, remaja takut gagal; takut dicemoohkan, dan takut berbeda dengan yang lain. Terlepas dari usia anak, ciri khas yang penting pada semua rangsangan takut adalah bahwa hal itu terjadi secara mendadak dan tidak diduga-duga dan anak hanya memiliki kesempatan yang kecil sekali untuk menyesuaikan diri dengan situasi (8). Ketidakmampuan mengendalikan pikiran buruk yang berulang-ulang dan kecenderungan berpikir bahwa keadaan akan semakin memburuk merupakan dua ciri penting dari rasa cemas (1).

Orang dengan kecemasan jika menghadapi situasi yang tampak berbeda di luar kendali. Situasi baru harus kita atur dan dipadukan dengan pandangan mengenai dunia dan diri sendiri. Perasaan tidak berdaya dan tidak mampu mengendalikan apa yang terjadi merupakan pokok dari teori kecemasan (9).

Keanekaragaman ungkapan seksual di dunia untuk menyembunyikan suatu penyamarataan pokok yang dapat diterapkan tanpa pengecualian bagi semua peraturan sosial seperti adat istiadat, budaya, dan aturan perilaku seksual. Sosialisasi dan penerimaan sosial memengaruhi sikap perilaku seksual dan pilihan perilaku. Aturan sosial menentukan sikap dan perilaku ini berhubungan erat dengan budaya atau norma (10).

Kegagalan dalam mengikuti peraturan berdampak pada sejumlah hukuman yang mungkin diterima, salah satunya adalah dikucilkan dari kelompok $(11,12)$. Teori norma sosial berpendapat bahwa perilaku individu sering dipengaruhi persepsi bagaimana anggota lain dalam kelompok berpikir dan bertindak (13).

Penundaan dan penolakan hubungan seksual pada remaja terkait dengan keyakinan diri (self efficacy) untuk mengevaluasi terhadap kemampuan atau kompetensi untuk melakukan suatu perilaku dan atau mengatasi hambatan. Self efficacy mempunyai dampak untuk menegosiasikan keamanan seks, menghambat tekanan untuk melakukan hubungan seks, menunda intercourse, menolak aktivitas seks berisiko (14).

Menurut teori kognitif sosial Bandura, keyakinan efikasi diri dapat memengaruhi pilihan orang dalam menjalankan tindakan yang remaja kejar. Individu cenderung berkonsentrasi dalam tugas yang remaja rasakan dan percaya menyelesaikan dan menghindari tugas yang tidak dapat remaja kerjakan. Keyakinan efikasi membantu menentukan sejauh mana usaha yang akan dikerahkan dalam suatu aktivitas, seberapa lama kegigihan ketika menghadapi rintangan dan seberapa ulet remaja akan menghadapi situasi yang tidak cocok. Keyakinan efikasi memengaruhi stres dan kecemasan individu (15).

Efikasi diri yang kuat meningkatkan kecakapan seseorang dan kesejahteraan (well-being) dalam cara yang tak terbayangkan. Individu yang percaya diri, memandang tugas-tugas yang sulit sebagai tantangan daripada sebagai ancaman untuk dihindari. Remaja memiliki minat yang lebih kuat dan keasyikan yang mendalam pada kegiatan, menyusun tujuan yang menantang remaja, dan memelihara komitmen kuat dan mempertinggi dan mendukung usaha remaja dalam menghadapi kegagalan. Remaja lebih cepat memulihkan percaya diri setelah mengalami kegagalan atau kemunduran. Efikasi diri yang tinggi membuat perasaan tenang.

Perilaku promiskuitas dapat menimbulkan dampak negatif pada remaja, (1) dampak psikologis berupa perasaan marah, takut, cemas, depresi, rendah diri, bersalah dan berdosa, (2) dampak fisiologis seperti penurunan konsentrasi, (3) dampak sosial misalnya tekanan dari masyarakat yang mencela dan menolak keadaan tersebut, dan (3) dampak fisik meliputi perkembangan penyakit menular seksual di kalangan remaja, dengan frekuensi penderita penyakit menular seksual (PMS) yang tertinggi antara usia 15-24 tahun. Infeksi penyakit menular seksual dapat menyebabkan kemandulan dan rasa sakit kronis dan meningkatkan risiko terkena PMS (1).

Gonore adalah penyakit menular serupa dengan klamidia, ditularkan melalui hubungan seks vaginal, oral atau anal. Penyakit ini telah berhasil diobati dengan antibiotika, namun gonore yang tidak segera diobati dapat menyebabkan nyeri panggul, keputihan dan radang panggul. Pada penderita penyebabnya adanya kuman Neisseria Gonorrhoeae. Pada penderita perempuan terkadang sering tanpa ada gejala atau gejala sulit dilihat, terkadang ada nyeri di bagian perut bawah, disertai keputihan dengan bau menyengat, alat kelamin terasa sakit atau gatal, adanya rasa sakit atau panas pada waktu buang air dan pendarahan setelah melakukan hubungan seks. Akan tetapi Gonore (GO) sering datang tanpa keluhan atau gejala apapun pada perempuan. Pada penderita laki-laki gejala yang timbul pada waktu satu minggu seperti rasa sakit pada saat buang air atau ereksi, keluar nanah dari saluran kencing utamanya pada pagi hari. Sering tanpa gejala pada stadium dini (7). 
Hepatitis menyebabkan peradangan hati dan dapat berlanjut menjadi sirosis hati atau kanker hati. Hepatitis B merupakan satu-satunya penyakit menular seksual yang dapat dicegah dengan vaksinasi. Hepatitis B dapat menyebabkan penyakit kuning, kelelahan yang teramat sangat, muntah-muntah dan demam, dapat ditularkan dengan mudah melalui kontak seksual. Sebagian penderita hepatitis B dapat kembali sehat dengan terapi anti hepatitis, namun sebagian penderita terkadang justru bertambah kronis (16).

\section{SIMPULAN}

Sikap permisif remaja pada perilaku seksual dipengaruhi rekan satu grup atau rekan sebaya. Kesadaran remaja yang rendah tentang bahaya promiskuitas, orientasi mencari kesenangan dan rasa ingin tahu yang besar menjadi pemicu perilaku promiskuitas remaja. Keyakinan diri dan pengalaman akan dampak perilaku promiskuitas menjadi faktor dominan agar remaja tidak mengulangi perilaku tersebut. Dampak perilaku promiskuitas remaja antara lain dikucilkan, gonnorhea, sifilis, chlamydia, herpes genitalis, HIV/AIDS dan penyakir menular seksual lain. Perlunya pendidikan seksual dan pengawasan kepada remaja terhadap aturan sehingga meminimalisir celah waktu dan tempat perilaku promiskuitas.

\footnotetext{
Abstrak

Tujuan: Penelitian ini bertujuan untuk memperoleh gambaran tentang faktor peendorong munculnya perilaku seksual promiskuitas dan dampaknya pada remaja laki-laki di kecamatan Wirobrajan, kota Yogyakarta. Metode: Penelitian kualitatif melalui desain studi kasus. Pengambilan subjek secara snowball sampling. Data dianalisis dengan content analysis. Hasil: Sikap permisif terhadap perilaku seksual yang dimiliki remaja akan berdampak mudah terpengaruh ajakan perilaku promiskuitas. Pengaruh dari rekan satu grup atau rekan sebaya sangat dominan dalam perilaku promiskuitas remaja. Kesadaran remaja yang kurang tentang bahaya perilaku promiskuitas, orientasi mencari kesenangan dan rasa ingin tahu yang besar menjadi pemicu perilaku promiskuitas remaja dengan memanfaatkan celah aturan dan kontrol yang lengah. Keyakinan diri dan pengalaman akan dampak dari perilaku promiskuitas menjadi faktor dominan agar remaja yang berperilaku promiskuitas tidak mengulangi perilaku tersebut. Dampak
}

perilaku promiskuitas remaja antara lain dikucilkan, gonnorhea, sifilis, dan herpes genitalis dan penyakit menular seksual lain. Simpulan: Perlu pengawasan dari berbagai sektor dan penegakan peraturan agar perilaku dan dampak promiskuitas diminimalisasi, pengawasan pergaulan remaja membawa dampak terhadap perilaku remaja.

Kata kunci: remaja; promiskuitas

\section{PUSTAKA}

1. Sarwono WS. Psikologi sosial, psikologi kelompok dan psikologi terapan Balai pustaka;2011.

2. Babakhani N. The effects of social skills training on self-esteem and aggression male adolescents. Procedia-Social and Behavioral Sciences. 2011 Jan 1;30:1565-70.

3. Musthofa SB, Winarti P. Faktor yang mempengaruhi perilaku seks pranikah mahasiswa di Pekalongan tahun 2009-2010. Jurnal Kesehatan Reproduksi. 2010;1(1 Des):32-41.

4. Team R. Gambaran Perilaku Seksual Dengan Orientasi Heteroseksual Mahasiswa Kos Di Kecamatan Jatinangor-Sumedang. Majalah Keperawatan Unpad. 2012 Apr 14;10(18).

5. Soetjiningsih S. Tumbuh Kembang Remaja dan Permasalahannya. Sagung Seto. Jakarta. 2004;320.

6. BKKBN. Program KB di Indonesia;2008.

7. Loekmono L. Rasa Percaya Diri Sendiri. Salatiga: Pusat Bimbingan Universitas Kristen Satya Wacana. 1983.

8. Hurlock EB. Perkembangan anak. Erlangga; 1978.

9. Atkinson RC, Hilgar ER. Pengantar psikologi, diterjemahkan oleh Nurjanah Taufik dan Rukmini. Barhana. Erlangga. Jakarta. 1996.

10. Simon W. Sexual conduct: The social sources of human sexuality. Routledge; 1973.

11. Deutsch M, Gerard HB. A study of normative and informational social influences upon individual judgment. The journal of abnormal and social psychology. 1955 Nov;51(3):629.

12. Perkins HW, Berkowitz AD. Perceiving the community norms of alcohol use among students: Some research implications for campus alcohol education programming. International journal of the Addictions. 1986 Jan 1;21(9-10):961-76.

13. Berkowitz L. Agresi 1: sebab dan akibatnya. Pustaka Binaman Pressindo; 1995.

14. Buhi ER, Goodson P. Predictors of adolescent sexual behavior and intention: A theory-guided systematic review. Journal of Adolescent Health. 2007 Jan 1;40(1):4-21.

15. Pajares F, Miller MD. Role of self-efficacy and self-concept beliefs in mathematical problem solving: A path analysis. Journal of educational psychology. 1994 Jun;86(2):193.

16. Tallis F. Mengatasi Rasa Cemas. Alih Bahasa: Mitasara Tjandra. Jakarta : Arcan;1991. 
Berita Kedokteran Masyarakat, Volume 33 No. 1 Tahun 2017 